\title{
EFFECTS OF SUNFLOWER SEEDS ON CHOLESTEROL AND LOW-DENSITY LIPOPROTEIN LEVELS IN PATIENTS WITH DYSLIPIDEMIA
}

\author{
CHEENAM B ${ }^{1}$, LEENA $P^{2}$, VIKAS $\mathrm{K}^{3}$ \\ ${ }^{1}$ Department of Clinical Nutrition, Fortis Escorts Hospital, Amritsar, Punjab, India. ${ }^{2}$ Department of Botany, Seth G.L. Bihani S.D (P.G.) \\ College, Sri Ganganagar, Rajasthan, India. ${ }^{3}$ Department of Food Technology and Nutrition, Lovely Professional University, Phagwara, \\ Punjab, India. Email: cheenam.bhatia89@gmail.com/leena.parihar@gmail.com
}

Received: 26 December 2018, Revised and Accepted: 21 January 2019

ABSTRACT

Objective: The present study was conducted with a goal to analyze and assess the effect of sunflower seeds on the serum cholesterol and low-density lipoprotein (LDL) levels.

Methods: A total of 60 patients comprising 34 males and 26 females were selected for the given study. The patients were divided into case and control groups. Various anthropometric measurements such as weight, height, and blood pressure along with certain biochemical parameters including cholesterol and LDL were recorded for these patients pre- and post-supplementation of $2 \mathrm{~g}$ of sunflower seeds for 6 months.

Results: The patients in the experimental group showed a significant and rapid difference $(\mathrm{p}<0.05)$ in comparison to the control intervention. The cholesterol levels in the case group reduced from $254.6 \pm 21.40$ to $183.40 \pm 3.01 \mathrm{mg} / \mathrm{dl}$, whereas, in control group, it reduced from $234.53 \pm 13.54$ to $194.50 \pm 6.16 \mathrm{mg} / \mathrm{dl}$. Similarly, the LDL levels in the case group decreased from $155.28 \pm 8.48$ to $122.70 \pm 2.94 \mathrm{mg} / \mathrm{dl}$; in contrast, in control group, it decreased from $159.53 \pm 6.04$ to $140.53 \pm 1.11 \mathrm{mg} / \mathrm{dl}$, respectively.

Conclusion: The study conducted concluded that sunflower seeds can be used as an adjuvant in treating the raised cholesterol and LDL levels in the blood serum which could otherwise lead various cardiac disorders (both major and minor).

Keywords: Sunflower seeds, Cholesterol, Low-density lipoprotein, Cardiac disorders, Supplementation, Nutrition-intervention.

(C) 2019 The Authors. Published by Innovare Academic Sciences Pvt Ltd. This is an open access article under the CC BY license (http://creativecommons. org/licenses/by/4. 0/) DOI: http://dx.doi.org/10.22159/ajpcr.2019.v12i3.31032

\section{INTRODUCTION}

Cardiovascular disease (CVD) has now become the leading cause of mortality in India. Premature mortality in terms of years of life lost due to CVD in India has increased by 59\%, from 23.2 million (1990) to 37 million (2010). Despite a wide heterogeneity in the prevalence of cardiovascular risk factors across different regions, CVD is emerged as a leading cause of death in all parts of India. Countering the epidemic requires the development of strategies such as the formulation and effective implementation of evidence-based policy, reinforcement of health system, and treatment with the use of both conventional and innovative techniques [1,2]. CVD occurs as a result of deranged serum lipid levels also known as dyslipidemia for long periods of time. Hence if the serum lipid levels are controlled the prevalence of CVD can also be controlled.

Dyslipidemia is the family of disorders that are characterized by abnormally high levels of lipids [3]. Cholesterol is a waxy substance that is not only present in some foods such as egg yolk, dairy, meat, fish, and poultry but is also produced by the body itself. However, when the cholesterol levels are raised in the body above the given range, the individual is more prone to develop a cardiac disorder [4].

Cholesterol being an oily consistency is insoluble in water. In the blood plasma, the only way that cholesterol can be transported is with the help of lipoproteins which are specific protein particles. The lipoproteins can be divided into four categories on the basis of their existing density: Very low-density lipoprotein (LDL), LDL, intermediate density lipoprotein, and high-density lipoprotein (HDL), respectively. These lipoproteins are the carriers of cholesterol all over the body [5]. When the level of cholesterol increases the level of lipoproteins in blood also increase simultaneously. The increase in the levels of the lipoproteins apart from that of HDL (also known as the good cholesterol), particularly, LDLcholesterol has been known to lead to various cardiovascular problems such as atherosclerosis [6]. The increased levels of LDL accredited to the consumption of inappropriate diet, thyroid, diabetes, obesity, genetic diseases, etc. [7].

Sunflower plant is a tall, erect, herbaceous annual plant that belongs to the family Asteraceae of the genus, Helianthus. The sunflower seeds prove to be a phenomenal source of minerals, vitamins, calories, and essential fatty acids. The seeds of the beautiful sunflower are majorly utilized in the edible oil extraction all over the world commercially. However, the seeds can be eaten as a delectable snack too $[8,9]$.

The sunflower seeds are not only nutty and delectable but also acknowledged as health food worldwide. The calorie-dense seeds get a large part of its calories from the fatty acids [8]. Especially, the seeds are rich in polyunsaturated fatty acids (PUFAs) specifically linoleic acid that accords about 50\% fatty acids in them. Apart from this, monounsaturated fatty acids (MUFAs) mainly oleic acid is also found in the seeds in a considerable amount. Research suggests that good amounts of MUFA and PUFA in the diet might prevent various cardiovascular disorders and deranged lipid profile [10].

Sunflower seeds are mainly used to extract oil which is majorly used for cooking or other culinary purpose in various parts of the world besides its use in cosmetic industries. The seeds of sunflower are well known for its physicochemical as well as its phytochemical potential as required by the human body such as Vitamin E, B complex Vitamins, essential fatty acids, and polyphenols. However, still lacking its identity in the pharmaceutical industries. Therefore, the present study is aimed to fulfil this gap using sunflower seeds as a pharmaceutical weapon 
for curing various deranged metabolic parameters including serum cholesterol and LDL levels.

The objective of the present study was to analyze the effects of sunflower seeds on the cholesterol and triglyceride levels of patients with dyslipidemia. The cholesterol evaluation includes total cholesterol and LDL.

\section{METHODS}

The samples of sunflower seeds of a variety of PSFH-67 were brought from the regional community market at Amritsar, Punjab, India. Around 130-200 mg average weight was recorded for the seeds. The seeds procured were placed in airtight container in sealed plastic bags until required.

The sunflower seeds were positioned on the turntable plate of the oven (Model: Samsung, CE104VD, 230 V-50 Hz, $2450 \mathrm{MHz}$, 100-900 W-6 Levels) after being placed in a single uniform layer in the $12-\mathrm{cm}$ diameter Pyrex Petri dishes. The contents of the dishes were then roasted at $150^{\circ} \mathrm{C}$ for $10 \mathrm{~min}$. Once the roasting was done, the seeds were kept to cool at room temperature [11].

The sample patients $(n=60 ; 28$ females and 32 males) were selected with the age ranging from 45 to 55 years from the state of Punjab (the sample patients were selected under the knowledge and due permission of the hospital administration). The group of sample patients was classified into two groups: Control and case groups (each group - $n=30$ ). The control group was given only the required diet counseling, whereas the case group was administered $2 \mathrm{~g}$ of sunflower seeds in addition to the required diet counseling.

A nutritional survey was done to collect the pre-supplementation data in both the groups - case and control - with the help of a self-prepared questionnaire. $24 \mathrm{~h}$ recall method was used for conducting the dietary survey. The anthropometric measurements and biochemical parameter estimation were conducted which included measurement of height, weight, and BMI in the former and recording the serum cholesterol and triglyceride level in the latter [12].

The 2 g roasted sunflower seeds were fed to the control group for 6 months. The pre- and post-supplementation data were recorded, and the serum cholesterol levels with the LDL levels were checked at each month end.

\section{Statistical analysis}

Data gathered from the sample patients were checked and analyzed using SPSS version 18. Results were presented as mean \pm standard deviation. A statistical analysis between the two visits was also performed using t-test. $\mathrm{p}<0.05$ was considered to be statistically significant for all analysis.

\section{RESULTS}

The effect of control and sample intervention has been studied on a group of 30 patients, and the data so obtained regarding the cholesterol

Table 1: Effect of sunflower seeds on cholesterol and LDL levels

\begin{tabular}{llllll}
\hline Visit & \multicolumn{2}{l}{ Cholesterol $(\mathrm{mg} / \mathbf{d l})$} & \multicolumn{2}{l}{ LDL $(\mathrm{mg} / \mathbf{d l})$} & \\
\cline { 2 - 3 } \cline { 5 - 6 } & Control & Case & Control & Case \\
\hline 1. & $* 234.53 \pm 13.54^{\mathrm{a} * *}$ & $254.26 \pm 21.40^{\mathrm{a}}$ & & $159.53 \pm 6.04^{\mathrm{a}}$ & $155.28 \pm 8.48^{\mathrm{a}}$ \\
2. & $223.13 \pm 10.01^{\mathrm{a}}$ & $229.33 \pm 15.31^{\mathrm{b}}$ & & $153.60 \pm 5.98^{\mathrm{a}}$ & $140.76 \pm 5.22^{\mathrm{b}}$ \\
3. & $215.80 \pm 12.55^{\mathrm{b}}$ & $196.83 \pm 10.56^{\mathrm{c}}$ & $148.93 \pm 3.30^{\mathrm{a}}$ & $134.00 \pm 6.58^{\mathrm{c}}$ \\
4. & $201.0 \pm 8.57^{\mathrm{c}}$ & $189.96 \pm 5.15^{\mathrm{c}}$ & & $146.20 \pm 3.96^{\mathrm{a}}$ & $129.00 \pm 3.14^{\mathrm{c}}$ \\
5. & $195.30 \pm 10.44^{\mathrm{c}}$ & $185.40 \pm 4.11^{\mathrm{c}}$ & & $142.63 \pm 1.64^{\mathrm{b}}$ & $127.16 \pm 3.87^{\mathrm{c}}$ \\
6. & $194.50 \pm 6.16^{\mathrm{c}}$ & $183.40 \pm 3.01^{\mathrm{c}}$ & $140.53 \pm 1.11^{\mathrm{c}}$ & $122.70 \pm 2.94^{\mathrm{d}}$ \\
\hline
\end{tabular}

*Mean \pm SD $(n=30), a^{* *}$ different upper case superscripts in the same rows indicate the significant difference $(\mathrm{p}<0.05)$, LDL: Low-density lipoprotein and LDL are presented in Table 1 and Fig. 1. With control intervention, a gradual decrease (significant; $\mathrm{p}<0.05$ ) was observed in cholesterol after the third visit, whereas, in the case group, a significant difference was observed at every visit which might be due to the intervention of sunflower seeds in their diet as shown in Fig.1 and Fig.2. Similarly, in case of LDL, the levels with control intervention decreased gradually (significant, $\mathrm{p}<0.05$ ) but only after the fifth visit, whereas, in the case

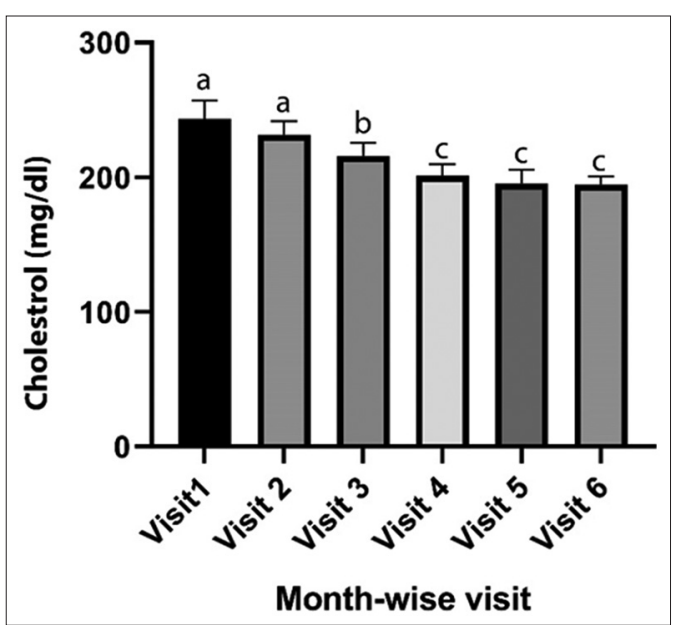

Fig. 1: Serum cholesterol levels in the control group

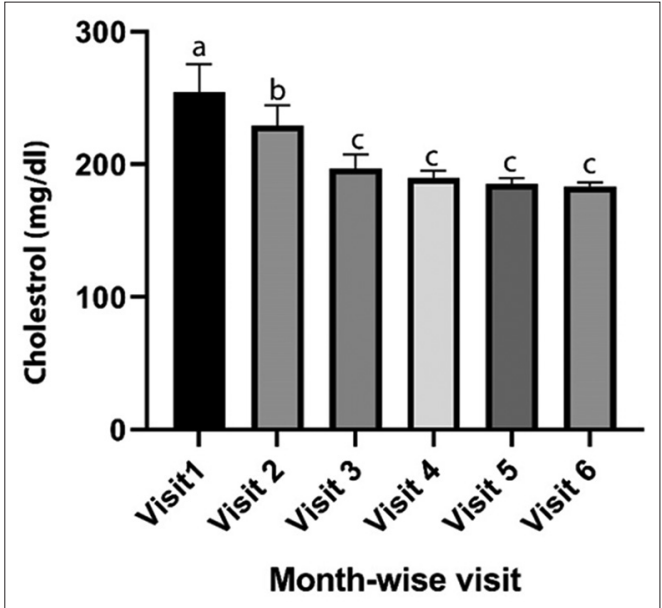

Fig. 2: Effect of sunflower seeds on serum cholesterol levels

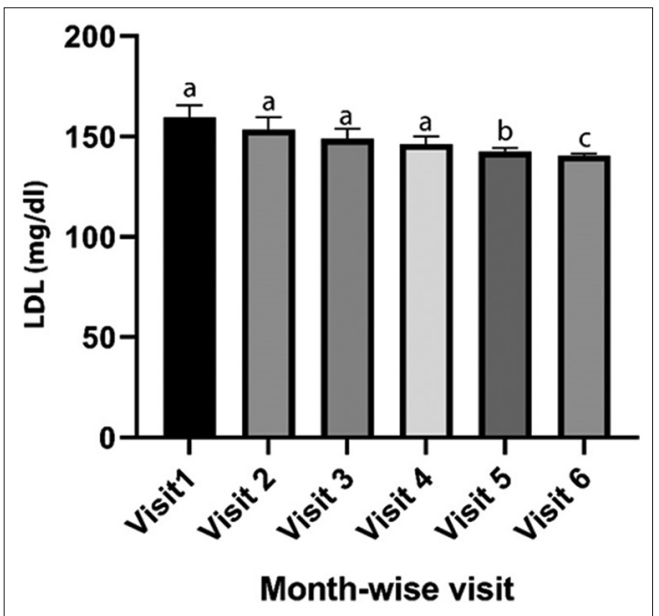

Fig. 3: Serum LDL levels in control group 


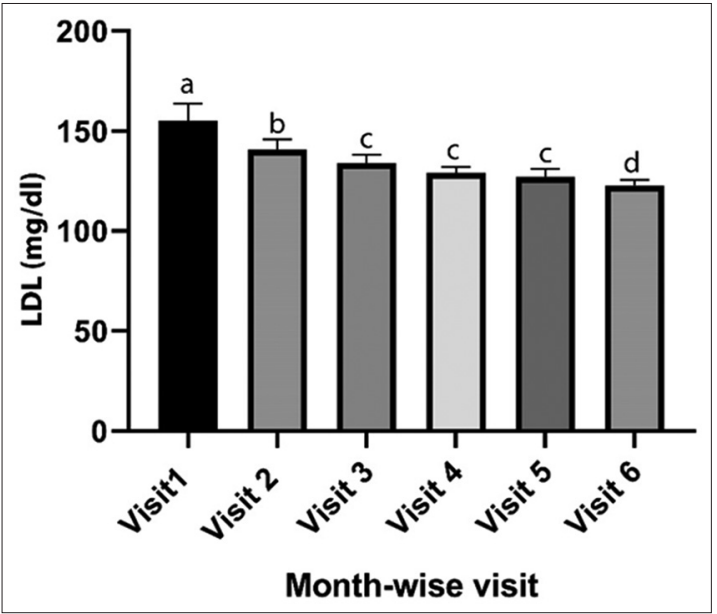

Fig. 4: Effect of sunflower seeds on serum low-density lipoprotein levels

group, a significant difference $(\mathrm{p}<0.05)$ was observed from the second visit itself as shown in Fig. 3 and Fig.4.

These days instead of pharmacological and ayurvedic treatments, the natural products are considered to be more reliable and useful. Although medicinal plants and natural products have always been regarded as healthy due to its rich therapeutic properties along with being $100 \%$ natural, in the past decade, the dependence on natural products has grown wide spread. Hence, sunflower seeds can be utilized as a home ingredient in lowering the lipid and cholesterol levels in the body which on other hand if not controlled would contribute to the ever growing death rate as result of CVD.

\section{DISCUSSION}

As per the results, the sunflower seeds have proved to show a positive and a better effect in reducing the cholesterol levels in patients with dyslipidemia along with a good decrease in LDL levels which otherwise might lead to hardening of the arteries and hence lead to cardiac disorders or even myocardial infarct. Just half a spoon of sunflower seeds every day provides the recommended level of proteins, vitamins, minerals, and phenolic antioxidants.

Among other studies, flax seeds were used to analyze their effectiveness to reduce the deranged cholesterol levels. A randomized crossover design was put to use in the study. 9 obese and dyslipidemic patients were selected who were made to consume $40 \mathrm{~g}$ of ground flax seeds every day for 84 days which included a 4 week washout period. The result of the study did not support the decrease in the cholesterol level strongly as per the antioxidant activity of flax seeds [13].

In another study, the effect of fenugreek was analyzed on the cholesterol and blood sugar levels. The fenugreek seeds were powdered and around $15 \mathrm{~g}$ was soaked in water and administered to the patients. The results showed a good decrease in the insulin level in NIDDM patients, but no statistical significance was found. Furthermore, fenugreek was not found to show any good effect on the lipid levels $3 \mathrm{~h}$ post-meals. A potential benefit in the treatment of diabetes was found, but no effect was found in dyslipidemia $[14,15]$.

In the above studies, flax seeds do not show a good effect on blood glucose levels whereas fenugreek seeds do show a good effect. But in spite of its blood glucose lowering effect it does not show good results in lowering serum lipid levels. Furthermore, fenugreek seeds used in the study are about $15 \mathrm{~g}$ per day which is much higher than the quantity of sunflower seeds shown in the present study ( $2 \mathrm{~g})$. Sunflower seeds have about $3 \mathrm{~g}$ of fiber and $5 \mathrm{~g}$ of protein in an ounce of kernels apart from the other benefits [16]. Thus, a small amount of sunflower seeds taken on a regular basis say being added on top of salads, in the vegetable mixtures, and in oats or other cereals or can be taken as it is as a health snack (in moderation).

All the more herbal products have been known to significantly decrease the level of cholesterol and LDL in the blood along with the atherogenic index [17]. Furthermore, general masses these days show better trust in herbal products than the regular medications.

\section{CONCLUSION}

The prevalence of dyslipidemia, a major cause for coronary heart disease, is very high in India. The relationship between dyslipidemia and occurrence of CVD has been already established. The control in serum lipid levels is very necessary to reduce the risk of CVD. The delicious sunflower seeds are highly considered to be health food and are substantial energy dense with $100 \mathrm{~g}$ of seeds delivering 583 calories. Being a phenomenal source of various health aiding vitamins, minerals, antioxidants, and other nutrients, they make a filling health snack. As per the results obtained in the given study, sunflower seeds can be recommended as an inordinate natural and household remedy to render control over the deranged cholesterol and LDL (bad cholesterol) in patients with dyslipidemia and thus can be used as a novel antihyperlipidemic agent.

\section{ACKNOWLEDGMENT}

We are very thankful to the management and MD of Fortis Hospital Amritsar for giving us the due permission to collect the required data from the selected sample patients.

\section{AUTHORS' CONTRIBUTIONS}

1. Preparation of questionnaire, sample selection, data collection, and data compilation - Cheenam Bhatia

2. Structure of the study and overall analysis - Dr. Leena Parihar

3. Statistical analysis - Dr. Vikas Kumar.

\section{CONFLICTS OF INTEREST}

They have no conflicts of interest.

\section{REFERENCES}

1. Prabhakaran D, Jeemon P, Roy A. Cardiovascular diseases in India: Current epidemiology and future directions. Circulation 2016;133:1605-20.

2. Niharika V. Introduction to hyperlipidaemia and its treatment: A review. Int J Curr Pharm Res 2016;9:6-14.

3. Soutar AK, Naoumova RP. Autosomal recessive hypercholesterolemia. Semin Vasc Med 2004;4:241-8.

4. Austin MA, Hutter CM, Zimmern RL, Humphries SE. Familial hypercholesterolemia and coronary heart disease: A HuGE association review. Am J Epidemiol 2004;160:421-9.

5. Carmena R, Duriez P, Fruchart JC. Atherogenic lipoprotein particles in atherosclerosis. Circulation 2004;109:32-7.

6. Kontush A, Chapman MJ. Antiatherogenic small, dense HDL-guardian angel of the arterial wall? Nat Clin Pract Cardiovasc Med 2006;3: 144-53.

7. Allain CC, Poon LS, Chan CS, Richmond W, Fu PC. Enzymatic determination of total serum cholesterol. Clin Chem 1974;20:470-5.

8. Ansminger AH, Ensminger ME, Kondale JE, Robson JR. Foods and Nutrition Encyclopedia. 2nd ed. California: Pegus Press Publishers; 1983.

9. Krimer MV, Madarev PS, Vastag Z, Preedy V, Patel V, Ronald W. Nuts and Seeds in Health and Disease Prevention. $1^{\text {st }}$ ed. St. Louis, Mo: Elsevier Publications; 2011.

10. Phillips KM, Ruggio DM, Ashraf-Khorassani M. Phytosterol composition of nuts and seeds commonly consumed in the United States. J Agric Food Chem 2005;53:9436-45.

11. Yoshida H, Takagi S, Mitsuhashi S. Tocopherol distribution and oxidative stability of oils prepared from the hypocotyl of soybeans roasted in a microwave oven. J Am Oil Chem Soc 1999;76:915-20.

12. Shafiya SK, Naga SS, Mohan CU, Divya P. Assessment of the nutritional behaviour among college students-a survey. Int J Pharm Pharm Sci 2018;10:1-6. 
13. Prasad K. Dietary flax seed in prevention of hypercholesterolemic atherosclerosis. Atherosclerosis 1997;132:69-76.

14. Kassaian N, Azadbakht L, Forghani B, Amini M. Effect of fenugreek seeds on blood glucose and lipid profiles in Type 2 diabetic patients. Int J Vitam Nutr Res 2009;79:34-9.

15. Madar Z, Abel R, Samish S, Arad J. Glucose-lowering effect of fenugreek in non-insulin dependent diabetics. Eur $\mathrm{J}$ Clin Nutr
$1988 ; 42: 51-4$

16. Wood C, Rebecca S. The Whole Foods Encyclopaedia. $1^{\text {st }}$ ed. New York: Prentice-Hall Press; 1988.

17. Leenawaty L, Renny I, Ekawati D, Sulistiawatid E, Herawati I, Dumilah R, et al. Hypocholesterolemic effect and pigments composition of herbal medicine containing higher and lower plants. Int J Pharm Pharm Sci 2017:9:97-103. 